\title{
III - Philippe Goujard (1946-2008)
}

\section{Claude Mazauric}

\section{(2) OpenEdition \\ Journals}

\section{Édition électronique}

URL : https://journals.openedition.org/ahrf/10756

DOI : $10.4000 /$ ahrf.10756

ISSN : 1952-403X

Éditeur :

Armand Colin, Société des études robespierristes

Édition imprimée

Date de publication : 1 janvier 2009

Pagination : 208-211

ISBN : 978-2-200-92557-4

ISSN : 0003-4436

Référence électronique

Claude Mazauric, « III - Philippe Goujard (1946-2008) », Annales historiques de la Révolution française [En ligne], 355 | janvier-mars 2009, mis en ligne le 01 janvier 2012, consulté le 24 avril 2022. URL : http://journals.openedition.org/ahrf/10756 ; DOI : https://doi.org/10.4000/ahrf.10756 
Expliquer ma familiarité avec Philippe Goujard suppose le rappel de ce simple fait : notre fréquentation remonte à plus de quarante années ! J'ai découvert Philippe au lycée Corneille quand il préparait le baccalauréat et que j'y étais un professeur enthousiaste de trente-trois ans; nos relations ont ensuite repris au tournant de 1968 quand Philippe, au sortir de la classe préparatoire du lycée Jeanne d'Arc, rejoignit l'Institut d'his- 
toire de la Faculté des Lettres où j'enseignais comme Maître-assistant; elles devinrent de plus en plus proches et confiantes au cours de l'année 1969-1970 quand Philippe, à la tête d'une brillante équipe, s'apprêtait à être admis à l'agrégation d'histoire dont j'assurais une part de la préparation; peu après, à mon instigation, il rejoignit à la Sorbonne le séminaire d'Albert Soboul à qui je l'avais présenté et dont il devint l'un des plus fidèles disciples jusqu'au décès de Soboul en 1982, notamment en rédigeant plusieurs textes pour les Annales historiques de la Révolution française et pour le Dictionnaire historique de la Révolution française. C'est dans ce cadre qu'il soutint et publia sa première thèse (1976) consacrée à l'abolition des vestiges de la féodalité dans le Pays de Bray, un ouvrage dans lequel il contribua à nourrir la théorie soboulienne de la « voie française », spécifiquement bourgeoise et paysanne, de passage au capitalisme et à la société libérale contemporaine. De cette incursion initiale dans l'histoire de la Révolution, Philippe Goujard a gardé un intérêt permanent pour son historiographie, ne refusant jamais de prendre part aux grands débats comme ceux qui ont accompagné le Bicentenaire. Membre fidèle de la Société des études robespierristes depuis 1974, il lisait avec attention et passion les numéros successifs des $A H R F$ dont il discutait toujours le contenu, non sans vivacité, à sa manière.

Devenu notre collègue à l'Université de Rouen après une bataille homérique où il fallut imposer la reconnaissance de ses inestimables qualités d'historien, Philippe Goujard devint l'un des piliers de notre département d'histoire et de nos centres de recherches successifs, comme le rappelle judicieusement Jean-Claude Vimont dans l'hommage qu'il consacre ici à sa mémoire. J'ai toujours admiré chez Philippe Goujard, l'historien, l'incomparable "imagination des sources» dont il faisait preuve : depuis les austères relevés de « rentes constituées » qu'il exploita pour sa maîtrise dirigée par André Corvisier, aux lourds dossiers de la série L des Archives départementales, des volumineux registres des insinuations ecclésiastiques, aux procès-verbaux des visites pastorales à Rouen ou à Liège, puis aux comptes des « fabriques », aux récits divers de vies ou de groupes qu'il repérait dans les bibliothèques, jusqu'aux plus éparses feuilles émanant des juridictions ecclésiastiques et laïques, un flot inlassablement renouvelé de dépouillements poursuivis dans la furia de son inépuisable curiosité, a permis à Philippe Goujard de démontrer à ceux qui croient le contraire, que l'histoire ne s'élabore jamais hors de ce qui témoigne de ces réalités passées qui ont laissé traces et trous, matériaux et spectres! Mais c'est aussi pourquoi Philippe Goujard a pu construire de si belles synthèses, comme cette Normandie aux XVI et 
XVII siècles, chef d'œuvre authentique et limpide qui se signale par la hauteur de vue, la précision analytique et l'exhaustivité thématique de l'enquête.

Me permettra-t-on d'insister sur une particularité remarquée des choix de Philippe Goujard et de son travail d'historien ? Lui qui était plus un incroyant qu'un mécréant, s'était pris après 1982 d'une vraie passion, sincère et profonde, pour l'histoire religieuse. Sa thèse, dont nous obtînmes qu'elle fût publiée par le CTHS en 1996, puis son grand livre, novateur, intelligent, informé, consacré à l'Europe catholique au XVIII ${ }^{\mathrm{e}}$ siècle, paru aux Presses Universitaires de Rennes, ont marqué une historiographie qui était jusqu'alors plutôt le fait de croyants affichés. À l'invitation de mon épouse qui dirigeait alors l'École doctorale de l'Université de Nancy 2, il vint en 2005 à Nancy présenter une conférence sur «Les processus de laïcisation de la vie publique en Europe au temps des Lumières $»$ : elle impressionna les auditeurs. Dans la conversation qui suivit, Philippe énonça cette vérité à la fois philosophique et méthodologique, savoir que le champ de la connaissance est ouvert à tous et que rien ne serait plus dommageable à la démocratie et à l'histoire comme discipline à vocation scientifique, que la monopolisation de la recherche par celles et ceux qui, au nom de la mémoire et de l'institution, s'en prétendraient les héritiers ou les propriétaires ! À cela se mesure le rationalisme créateur, et affranchi des poncifs, de l'historien qu'il n'a cessé d'être. Mais c'est aussi ce qui explique cette propension à aller voir ailleurs qui a marqué son génie propre, sa connaissance de la piété populaire en Savoie, ses observations poursuivies sur le terrain en Catalogne, sa passion des littératures lointaines, ses pérégrinations dans la culture juive de Ruthénie ou d'Ukraine, ses incursions dans le modèle constitué par le féodalisme nippon d'avant l'ère du Meiji, et même son érudite connaissance du cinéma noir américain des années cinquante, etc.

Depuis notre départ de Rouen à Nancy en 1999, puis à Nîmes, nous ne nous retrouvions qu'occasionnellement. Mais nous ne nous perdions pas de vue, communiquant par courrier postal ou par téléphone, presque jamais par courriel, ce qui est devenu rare ! Lui qui toujours changeait de pied dans le travail, ne perdait pas le contact avec ceux qu'il estimait et qui l'estimaient, multipliant les interpellations, alignant les paradoxes et les questionnements qui dérangent la vie routinière, y compris la vie politique au jour le jour... Les rapports qui nous unissaient depuis si longtemps étaient fraternels. À certains moments de nos existences, ils prirent même une dimension que je qualifierais de filiale, car il en eut momentanément besoin et je lui devais bien cela! Il reste surtout que 
Philippe Goujard a honoré de son talent et de sa créativité jamais prise en défaut, l'Université de Rouen, mais aussi toute l'historiographie française des temps dits « modernes ». Sa disparition bouleverse ses amis et crée un vide sensible et béant, à la mesure du manuel qu'il achevait pour Armand Colin, dont il croyait encore possible l'été dernier de pouvoir le mener à son terme, «à temps » me disait-il, et qui ne paraîtra pas, s'il paraît un jour, tel qu'il l'imaginait... En me séparant de lui par l'énoncé de ces quelques phrases, je veux honorer sa mémoire. Et, inspiré par le sentiment de gratitude pour tout ce qu'il nous a donné de grand ou de subtil, dire à ses collègues, ses proches et ses amis, les paroles de fraternité et d'admiration pour son œuvre d'historien, dont je ne doute d'ailleurs pas une seconde qu'il aurait attendu que nous les prononcions, nous qui lui survivons.

Claude MAZAURIC Professeur émérite de l'Université de Rouen 